\title{
Weber Green Staining Method
}

National Cancer Institute

\section{Source}

National Cancer Institute. Weber Green Staining Method. NCI Thesaurus. Code C85828.

A microscopy staining method that utilizes a modified trichrome stain to determine the presence of microspordial, sporulating species. The staining method utilizes

chromotrope $2 \mathrm{R}$, a red acidic dye, the counterstain fast green, and phosphotungstic acid. 